\title{
Hepatitis B and C virus prevalence in a rural area of South Korea: the role of acupuncture
}

\author{
HR Shin', JY Kim², JI Kim², DH Lee ${ }^{3}$ KY Yoo ${ }^{4}$, DS Lee ${ }^{5}$ and S Franceschi*,6 \\ 'Division of Cancer Control and Epidemiology, National Cancer Center Research Institute, 809 Madu-dong, Ilsan-Gu, Koyang, Kyonggi, 4 I I-764 South Korea; \\ ${ }^{2}$ Department of Preventive Medicine, College of Medicine, Dong-A University, I-3 Dong-Dae-Shin-Dong, Seo-Gu, Busan, 602-7I 4, South Korea; \\ ${ }^{3}$ Department of Preventive Medicine, College of Medicine, Kosin University, 34 Am-Nam-Dong, Seo-Gu, Busan, 602-702, Korea; ${ }^{4}$ Department of \\ Preventive Medicine, College of Medicine, Seoul National University, 28 Yongon-Dong, Chong-No-Gu, Seoul, 1 l 0-799, South Korea; ${ }^{5}$ Department of \\ Clinical Pathology, College of Medicine, Seoul National University, 28 Yeon-Keon-Dong, Chong-No-Gu, Seoul, I l 0-799, South Korea; ${ }^{6}$ Unit of Field \\ Intervention Studies, International Agency for Research on Cancer, 150 Cours Albert Thomas, F-69372 Lyon cedex 08, Lyon, France
}

A cross-sectional study evaluated the prevalence of and the risk factors for hepatitis $C$ and $B$ viruses among 700 adults above the age of 40 years in a rural area of South Korea. Seropositivity for hepatitis C virus antibody (1 .0\%, 95\% confidence interval: 8.7 - 13.6) was higher than that for hepatitis B surface antigen (4.4\%, 95\% confidence interval: $3.0-6.2)$. Anti-hepatitis $C$ virus seropositivity was associated with a history of repeated acupuncture (odds ratio $=2.1,95 \%$ confidence interval: 1.1 4.0), and blood transfusion (odds ratio $=5.5,95 \%$ confidence interval: $1.6-19.3$ ) before 1992 when hepatitis $C$ virus screening in blood donors became mandatory. Hepatitis $C$ virus $2 a$ was the most prevalent genotype, followed by Ib. Hepatitis $C$ virus risk attributable to acupuncture was 38\% (9\% for men and 55\% for women). Safer acupuncture practice has become a priority for hepatitis $C$ virus prevention in South Korea.

British Journal of Cancer (2002) 87, 314-3I8. doi:I0.1038/sj.bjc.6600436 www.bjcancer.com

(C) 2002 Cancer Research UK

Keywords: hepatitis C virus; hepatitis B virus; acupuncture; blood transfusion; South Korea

Liver cancer mortality in South Korea is one of the highest in the world at 30.3 and 9.7 per 100000 for men and women, respectively (world age-standardised WHO, 1998). Both hepatitis B and C viruses ( $\mathrm{HBV}$ and $\mathrm{HCV}$ ) infection are strong risk factors for the development of liver cancer in South Korea (Shin et al, 1996), as well as in other countries (IARC, 1994). In 1991, HBV was found to be the most important risk factor for hepatocellular carcinoma (HCC) in Korea (Yoo et al, 1991). Since then, however, HCV infection has shown a stronger association in elderly HCC patients (Lee et al, 1993; Huh et al, 1998).

Since the introduction of an HCV antibody (anti-HCV) test for screening blood donors in Korea in April 1991, HCV exposure among blood recipients has decreased. However, HCV transmission may still be prevalent in certain areas, due to such practices as acupuncture. Indeed, a history of acupuncture has been reported by more than one third of subjects in a study in South Korea (Shin et al, 2000). Major indications for acupuncture include arthritis and other joint diseases, the sequelae of trauma, headache, and a broad range of minor diseases not responding to conventional medical treatments (http://www.acu.pe.kr).

A survey in 1993 in a rural district showed a high prevalence of anti-HCV (5.5\% among subjects over 10 years of age) and suggested a role for parenteral viral exposure other than blood transfusion (Shin et al, 2000). We therefore conducted a crosssectional study in a different part of the same rural area.

* Correspondence: S Franceschi; E-mail: franceschi@iarc.fr

Received 8 March 2002; revised 29 April 2002; accepted 3 May 2002

\section{METHODS}

\section{Study area and subjects}

The study area was in a rural part of south-east Korea (population 4500 ) where mortality rates for liver cancer are $120 \%$ and $50 \%$ higher than the national average in men and women, respectively (Lee et al, 2001). The majority of the population in the study area is employed in agriculture, and their socio-cultural characteristics are similar to those in other rural areas in Korea.

In 1999, the 2299 inhabitants of the area over 40 years of age formed the target population for a survey in the preparation for a large prospective cohort study (Yoo et al, 2002). The survey aimed to assess the prevalence of, and risk factors for, infection with HBV, HCV and Clonorchis sinensis. Subjects were not individually invited, but were made aware of the survey by local health authorities and village heads (e.g., through village meetings and local broadcasting). Seven hundred subjects gave their informed consent and underwent the survey (288 men and 412 women, comprising $30.2 \%$ and $31.8 \%$ of male and female residents, respectively). Among these were 146 couples thereby allowing study of heterosexual transmission of HCV and HBV between spouses.

A structured questionnaire was completed for each individual by trained interviewers covering demographic characteristics, medical history including blood transfusion, acupuncture, smoking, and drinking habits.

The total frequency of blood transfusion and acupuncture sessions was evaluated. As screening for HCV among blood donors started in Korea in April 1991, the study participants were asked to report the year in which they first received blood transfusion and also acupuncture. Alcohol drinking was defined as regularly 
consuming at least one alcoholic drink per month. Daily intake of more than 80 grams of alcohol for more than 10 years was classified as heavy drinking. Individuals who had smoked more than 20 packs of cigarettes prior to the survey were classified as smokers and those who had smoked more than one pack per day for more than 10 years were classified as heavy smokers.

\section{Serological study}

Serum samples, frozen at $-70^{\circ} \mathrm{C}$ within $2 \mathrm{~h}$ of blood collection, were tested for anti-HCV and hepatitis B surface antigen (HBsAg). Anti-HCV was tested using the Abbott enzyme immunoassay (EIA) kit, HBsAg using the EIA method. The liver enzymes, alanine aminotransferase (ALT), and aspartame aminotransferase (AST) were also evaluated.

\section{Detection and genotyping of serum HCV RNA}

Presence of HCV RNA viremia was confirmed by nested reverse transcript-polymerase chain reaction (RT-PCR), using Roche Amplicor, the detection limit being 100 copies per ml. Hepatitis $\mathrm{C}$ virus genotypes $1 \mathrm{a}, 1 \mathrm{~b}, 2 \mathrm{a}, 2 \mathrm{~b}$ and $3 \mathrm{a}$ were determined by amplification of the core region using genotype-specific primers as described by Okamoto et al (1993).

\section{Statistical analysis}

Odds ratios (ORs) and corresponding 95\% confidence intervals (CIs) of being seropositive for anti-HCV or HBsAg were computed by means of unconditional multiple logistic regression analysis including age, sex, education, smoking habits, and history of blood transfusion and acupuncture (SAS Institute Inc, 1999). Linear trends in risk according to the increase of exposure were evaluated by likelihood ratio tests for trend based on linear logistic regression models. Adjusted attributable risk fractions were computed (Mezzetti et al, 1996).

\section{RESULTS}

\section{Seroprevalence of anti-HCV and HBsAg}

The seroprevalence of anti-HCV (11.0\%, 95\% CI: $8.7-13.6)$ was higher than that of HBsAg $(4.4 \%$, 95\% CI: 3.0-6.2) (Table 1). Seropositivity of anti-HCV in women $(14.1 \%)$ was more than two-folds higher than in men $(6.6 \%)$. The opposite was found for HBsAg-positivity (6.6\% in men, $2.9 \%$ in women). Seropositivity of anti-HCV increased with age $(P$ for trend $<0.001)$, while seropositivity for HBsAg decreased $(P=0.001)$ (Figure 1).

\section{Risk factors for HCV infection}

The association between seropositivity for anti-HCV and HBsAg and selected characteristics is shown in Table 1. After adjustment for all variables listed in Table 1 , the crude OR of anti-HCV in women decreased from 2.3 (95\% CI: $1.3-4.0$ ) to 1.3 (95\% CI: $0.6-3.0)$. In contrast, the crude OR of HBsAg in women increased from 0.4 (95\% CI: $0.2-0.9)$ to 1.5 (95\% CI: $0.4-5.1$ ).

Whereas education was inversely associated with the risk for anti-HCV seropositivity (OR for more than 10 years of education vs none $=0.3,95 \% \mathrm{CI}: 0.1-0.9)$, it was directly associated with HBsAg seropositivity ( $\mathrm{OR}=4.6,95 \% \mathrm{CI}$ : $1.1-19.1)$. Drinking alcohol was not significantly associated with seropositivity for either anti-HCV or HBsAg. An increased risk of borderline statistical significance was found for $\mathrm{HBsAg}$ among cigarette smokers (OR for heavy smoker $v s$ none=3.1, CI: $0.9-10.8$ ). A history of blood transfusion was not significantly associated with seropositivity for either anti-HCV or HBsAg.
Compared to individuals who had never been transfused, those with a history of transfusion before 1992 had an increased risk $(\mathrm{OR}=5.5,95 \% \mathrm{CI}: 1.6-19.3)$ for anti-HCV positivity but not for HBsAg positivity ( $\mathrm{OR}=1.5,95 \% \mathrm{CI}: 0.2-13.0)$ (Table 1$)$. None of the 10 recipients who were transfused in or after 1992 was positive for anti-HCV, but one subject was seropositive for HBsAg. Only one individual reported having a transfusion more than once. Blood volume was associated with seropositivity for neither antiHCV nor HBsAg. Whilst $13.3 \%$ of subjects with a history of acupuncture were seropositive for anti-HCV, only $4.0 \%$ showed HBsAg seropositivity. An association was found between acupuncture and anti-HCV seropositivity $(\mathrm{OR}=1.9,95 \% \mathrm{CI}$ : $1.0-3.6)$, but not HBsAg $(\mathrm{OR}=0.9)$. The increased risk from acupuncture did not vary by year at first exposure. OR for anti-HCV was higher among those who underwent acupuncture twice or more $(\mathrm{OR}=2.1,95 \%$ CI: $1.1-4.0)$ than among those who had this only once $(\mathrm{OR}=1.2)$ (Table 1).

\section{HCV RNA genotype}

HCV RNA was detected by RT-PCR in 51 (66.2\%) of 77 antiHCV positive subjects. The detection rate of HCV RNA among anti-HCV positive subjects was significantly lower in women (58.6\%) than in men $(84.2 \%)$. The most prevalent HCV genotype was $2 \mathrm{a}$ followed by $1 \mathrm{~b}$. Most subjects with HCV RNA detected had a history of acupuncture (Figure 2).

\section{Inter-spousal transmission of $\mathrm{HCV}$ infection}

In three of 146 couples who took part in this aspect of the study, seropositivity for anti-HCV was found in both partners (Table 2). In the only couple both partners were $\mathrm{HCV}$ RNA positive, HCV genotypes were different. All six members of anti-HCV positive concordant couples had a history of acupuncture. In only one couple were both spouses seropositive for HBsAg, both with a history of acupuncture, but not blood transfusion.

\section{DISCUSSION}

The major findings from our present study in South Korea are (1) a high prevalence of anti-HCV seropositivity, more than double that of HBsAg seropositivity and (2) that acupuncture is an important cause of this. Acupuncture was associated with a doubling in the prevalence of anti-HCV, but not of HBsAg.

As $34.1 \%$ of men and $62.9 \%$ of women reported having had an acupuncture session more than once, the attributable risk fraction for $\mathrm{HCV}$ infection was $38 \%$ (95\% CI: $8.0-69.5$ ) overall $(9.4 \%$, 95\% CI: $0.5-67.3$ among men and 54.5\%, 95\% CI: $21.2-87.8$ among for women). In contrast, the risk fraction attributable to blood transfusion was 4\% (95\% CI: $-3.2-11.1)$.

Seroprevalence of HCV infection varies widely between and within countries, ranging from $1-2 \%$ in most western countries (Dubois et al, 1997; Alter et al, 1999; Goritsas et al, 2000), and in non-endemic areas in Japan (Kiyosawa et al, 1994; Kayaba et al, 1998) to more than $15 \%$ in Egypt (Frank et al, 2000), Italy (Raffaele et al, 2001), and in endemic areas of Japan (Kiyosawa et al, 1994).

The only efficient route for HCV transmission is parenteral. As the prevalence of blood transfusion in the general population is less than $1 \%$, high-risk areas for HCV are characterised by a relatively high frequency of other parenteral treatments (e.g., intra-muscular injections for minor conditions in Italy before disposable needles and syringes became available, Raffaele et al, 2001).

Acupuncture, tattooing, and folk medicines have been associated with an increased risk of HCV seropositivity in several studies from Asia (see Kao and Chen, 2000, for a review), including Japan (Michitaka et al, 1991; Kiyosawa et al, 1994), Taiwan (Sun et al, 1999), Indonesia (Sulaiman et al, 1995) and South Korea (Shin 
Table I Seropositivity and corresponding odds ratio (ORs) and $95 \%$ confidence intervals (Cls) ${ }^{a}$ for anti-HCV and HBsAg according to selected characteristics, South Korea, 1999

\begin{tabular}{|c|c|c|c|c|c|}
\hline \multirow[b]{2}{*}{ Variables } & \multirow{2}{*}{$\begin{array}{l}\text { No. of } \\
\text { tested }\end{array}$} & \multicolumn{2}{|c|}{ Anti-HCV positivity } & \multicolumn{2}{|c|}{ HBsAg positivity } \\
\hline & & $n(\%)$ & OR (95\% Cl) & n (\%) & OR $(95 \% \mathrm{Cl})$ \\
\hline \multicolumn{6}{|l|}{ Age group } \\
\hline $40-49$ & 117 & $5(4.3)$ & 1.0 & $9(7.7)$ & 1.0 \\
\hline $50-59$ & 216 & $23(10.6)$ & $1.9(0.7-5.4)$ & $10(4.6)$ & $0.7(0.3-1.8)$ \\
\hline $60-69$ & 248 & $28(11.3)$ & $1.8(0.6-5.2)$ & $7(2.8)$ & $0.5(0.2-1.6)$ \\
\hline 70 & 119 & $21(17.7)$ & $2.6(0.8-8.1)$ & $5(4.2)$ & $1.3(0.3-4.9)$ \\
\hline$P$ for trend & & $<0.01$ & 0.17 & 0.11 & 0.82 \\
\hline \multicolumn{6}{|l|}{ Sex } \\
\hline Male & 288 & $19(6.6)$ & 1.0 & $19(6.6)$ & 1.0 \\
\hline Female & 412 & $58(\mid 4.1)$ & $1.3(0.6-3.0)$ & $12(2.9)$ & $1.5(0.4-5.1)$ \\
\hline \multicolumn{6}{|l|}{ Education } \\
\hline None & 249 & $44(17.7)$ & 1.0 & $4(1.6)$ & 1.0 \\
\hline$<10$ years & 300 & $27(9.0)$ & $0.6(0.3-1.1)$ & $15(5.0)$ & $3.4(0.96-11.9)$ \\
\hline$\geqslant 10$ years & $|5|$ & $6(4.0)$ & $0.3(0.1-0.9)$ & $12(8.0)$ & $4.6(1.1-19.1)$ \\
\hline$P$ for trend & & $<0.01$ & 0.02 & $<0.01$ & $<0.05$ \\
\hline \multicolumn{6}{|l|}{ Alcohol drinking } \\
\hline No & 444 & $53(11.9)$ & 1.0 & $15(3.3)$ & 1.0 \\
\hline Moderate & 155 & $18(9.9)$ & $1.3(0.7-2.5)$ & $9(5.0)$ & I.I $(0.4-2.8)$ \\
\hline Heavy & 120 & $5(7.8)$ & $1.5(0.5-4.6)$ & $7(10.9)$ & $2.3(0.8-7.2)$ \\
\hline$P$ for trend & & 0.26 & 0.3 & $<0.01$ & 0.2 \\
\hline \multicolumn{6}{|l|}{ Cigarette smoking } \\
\hline No & 425 & $57(13.4)$ & 1.0 & $12(2.8)$ & 1.0 \\
\hline Moderate & 155 & $13(8.4)$ & $0.7(0.3-1.5)$ & $8(6.9)$ & $1.8(0.5-6.1)$ \\
\hline Heavy & 120 & $7(5.8)$ & $0.6(0.2-1.6)$ & || (9.2) & $3.1(0.9-10.8)$ \\
\hline$P$ for trend & & $<0.01$ & 0.2 & $<0.01$ & 0.07 \\
\hline \multicolumn{6}{|l|}{ Blood transfusion } \\
\hline No & 662 & $70(10.6)$ & 1.0 & $29(4.4)$ & 1.0 \\
\hline Yes & 38 & $7(18.4)$ & $1.8(0.7-4.4)$ & $2(5.3)$ & $1.6(0.3-7.1)$ \\
\hline \multicolumn{6}{|l|}{ Year } \\
\hline 1992 and after & 10 & 0 & $0(0-1.3)$ & I (I0.0) & $2.4(0.2-21.5)$ \\
\hline Before 1992 & 14 & $5(35.7)$ & $5.5(1.6-19.3)$ & I (7.1) & $1.5(0.2-13.0)$ \\
\hline Not reported & 14 & $2(14.3)$ & I.I $(0.2-5.4)$ & 0 & $0(0-6.3)$ \\
\hline \multicolumn{6}{|l|}{ Volume $(L)$} \\
\hline 1 & 12 & $3(25.0)$ & $2.6(0.7-10.5)$ & $2(16.7)$ & $5.9(1.1-30.9)$ \\
\hline$\geqslant 2$ & 26 & $4(15.4)$ & $1.4(0.4-4.3)$ & 0 & $0(0-2.2)$ \\
\hline \multicolumn{6}{|l|}{ Acupuncture } \\
\hline No & 227 & $14(6.2)$ & 1.0 & $12(5.3)$ & 1.0 \\
\hline Yes & 473 & $63(13.3)$ & $1.9(1.02-3.6)$ & $19(4.0)$ & $0.9(0.4,2.0)$ \\
\hline \multicolumn{6}{|l|}{ Year } \\
\hline 1992 and after & 238 & $36(15.2)$ & $2.4(1.2-4.5)$ & II (4.6) & $1.0(0.4,2.0)$ \\
\hline Before 1992 & 98 & $17(17.4)$ & $3.0(1.4-6.7)$ & $4(4.1)$ & $0.8(0.2,2.5)$ \\
\hline Not exact & 137 & $10(7.3)$ & $0.8(0.4-2.0)$ & $4(2.9)$ & $0.8(0.2,2.6)$ \\
\hline \multicolumn{6}{|l|}{ Frequency } \\
\hline Once & 87 & $7(8.1)$ & $1.2(0.4-3.0)$ & $5(5.8)$ & I.I $(0.3-3.4)$ \\
\hline$\geqslant 2$ sessions & 386 & $56(14.5)$ & $2.1(1.1-4.0)$ & $14(3.6)$ & $0.8(0.4-2.0)$ \\
\hline$P$ for trend & & $<0.01$ & 0.02 & & \\
\hline Total & 700 & $77(11.0)$ & $(8.7-13.6)$ & $31(4.4)$ & $(3.0-6.2)$ \\
\hline
\end{tabular}

${ }^{a}$ Adjusted for age, sex, education, drinking, smoking, blood transfusion, and acupuncture, as appropriate.

et al, 2000). The relative risk in people after acupuncture ranged between 1.9 (Michitaka et al, 1991) and 3.3 (Shin et al, 2000) and tended to increase with the increase in acupuncture sessions. No increased risk of HCV infection after acupuncture, however, was found in Japan, among atomic bomb survivors (Fujiwara et al, 2000), the United Kingdom (Neal et al, 1994) and the United States (Alter, 1999), though in Western countries the practice was seldom reported (Alter, 1999). The proportion of people with a history of acupuncture in our survey in South Korea $(68 \%)$ is the highest reported so far in any study.

Our estimate of HCV seropositivity agrees with a previous survey (11\% among adults over 40 years old) (Shin et al, 2000), although it is higher than in other studies (Kim et al, 1992; Kim et al, 1997; Seo and Lee, 1998) from South Korea.
Conversely, our present estimate of HBsAg seropositivity is similar to that found by the 1998 National Health and Nutrition Survey in South Korea (KIHSA, 1999). In the mid-1980s a nationwide campaign of HBV vaccination was initiated in the country, the vaccine being mandatory for newborn children and recommended to adults (Ahn, 1996).

Apart from acupuncture and blood transfusion before routine $\mathrm{HCV}$ screening of blood donors, only a high educational level was significantly associated with $\mathrm{HCV}$ positivity in this study. Interestingly, whereas the excess of HCV positivity in women compared to men disappeared after allowance for acupuncture history, the inverse association with years of education was not modified. In fact, whereas women in South Korea showed a three-fold increased risk to have had acupuncture compared 
A

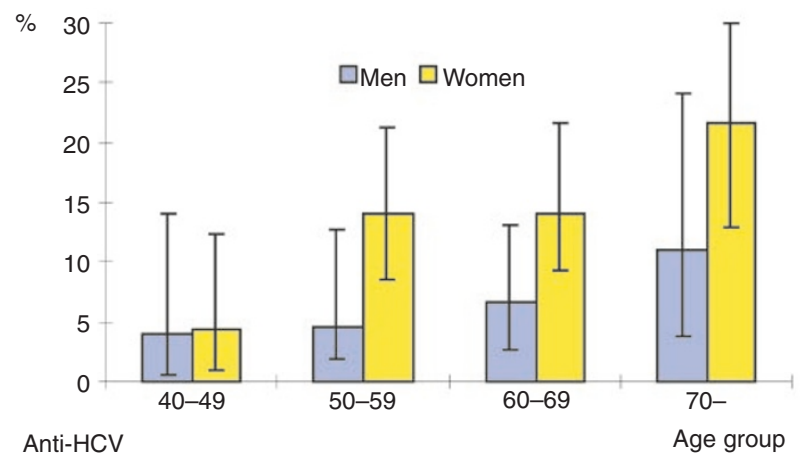

Anti-HCV

B

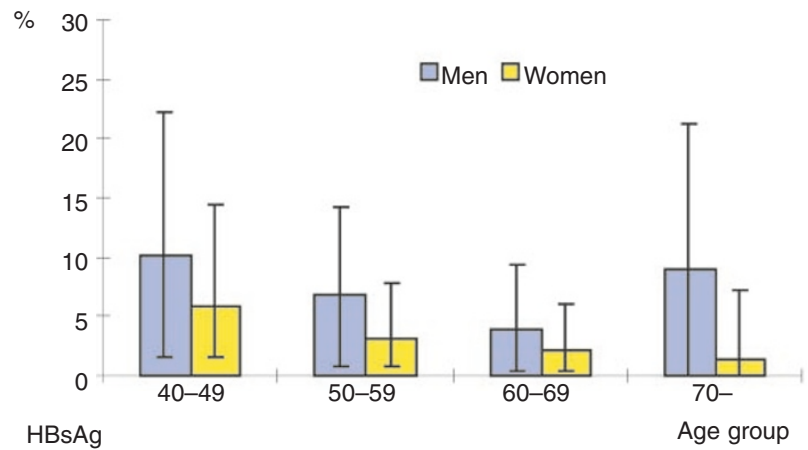

Figure I Seropositivity of anti-HCV (A) and HBsAg (B) among men and women, South Korea, 1999.
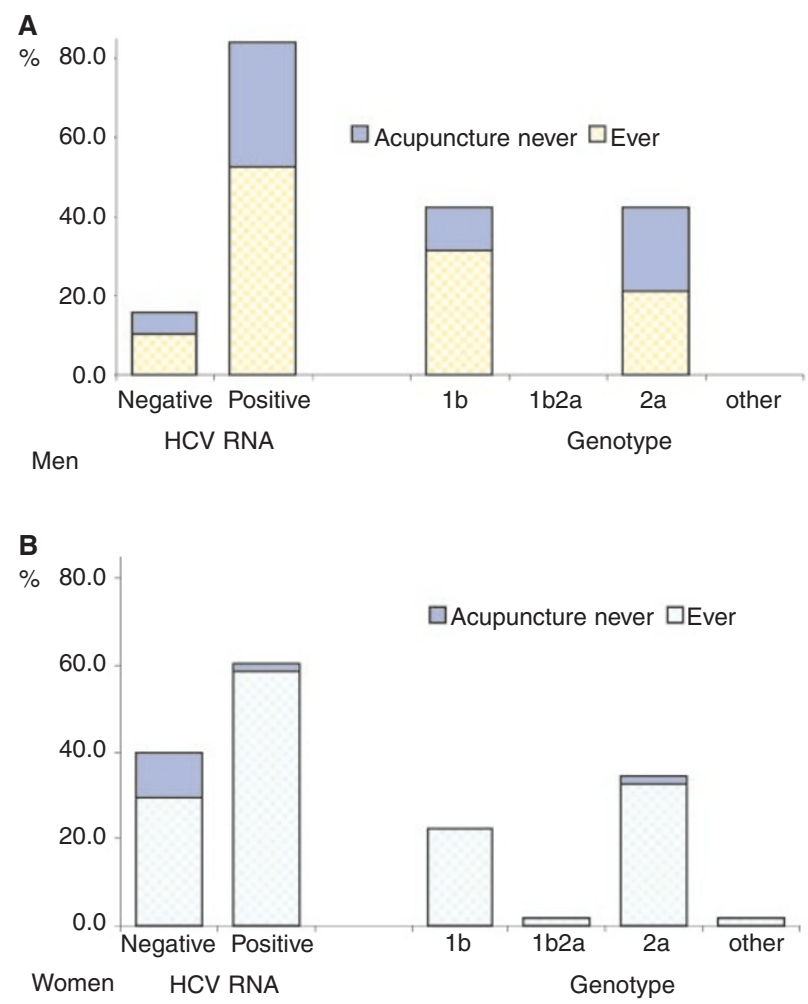

Figure 2 Distribution of HCV seropositive subjects by presence of HCV RNA, genotypes, and acupuncture history in men (A) and women (B), South Korea, 1999.
Table 2 Concordance of seropositivity for anti-HCV and HBsAg between spouses, South Korea, 1999

\begin{tabular}{lccc}
\hline & \multicolumn{2}{c}{ Husband } & \\
\cline { 2 - 3 } Wife & Positive & Negative & Total \\
\hline Anti-HCV & 16 & \\
Positive & $3^{\mathrm{a}}$ & 120 & 19 \\
Negative & 7 & 136 & 127 \\
Total & 10 & 146 \\
& \multicolumn{1}{c}{ McNemar's test $=3.52$} & $P=0.06$ \\
HBSAg & & 6 & \\
Positive & $1^{\mathrm{b}}$ & 129 & 7 \\
Negative & 10 & 135 & 139 \\
Total & 11 & 146 \\
& \multicolumn{2}{c}{ McNemar's test=1.0 } & $P=0.32$ \\
\hline
\end{tabular}

${ }^{a} \mathrm{HCV}$ RNA genotype and risk factors of three couples; Couple I: husband HCV RNA negative, blood transfusion history positive, wife genotype Ib; Couple 2: husband genotype Ib, wife genotype 2a; Couple 3: husband and wife both $\mathrm{HCV}$ RNA negative; All six subjects had a history of acupuncture. 'Husband and wife had a history of acupuncture, but not of transfusion.

to men, no clear difference in such practice emerged according to educational level.

The association with HCV seropositivity in our survey was stronger among those who underwent acupuncture twice or more than those who had it only once and was, therefore, unlikely to be due to chance. The association with HCV following first acupuncture after 1991 suggested that the transmission risk has persisted in recent years.

Possible bias and confounding factors may be relevant. Selection bias is of concern, as only one third of the population joined our health survey. The prevalence of HCV and, possibly, the association with acupuncture history might have been overestimated in our survey if people with liver disease or those being afraid of the possible dangers of acupuncture had selectively accepted to participate. We had, however, information on liver enzymes and found a high HCV seropositivity ( $5.4 \%$ in men, $11.5 \%$ in women) also among participants whose ALT levels were normal $(79.4 \%$ in men and $90.2 \%$ in women). Furthermore, in 1999 there was no widespread awareness of the possible danger of acupuncture in the general population in Korea and the level of use of acupuncture we report, is consistent with a previous survey (Shin et al, 2000). A confounding effect of parenteral treatments other than acupuncture and blood transfusion is difficult to rule out. Frequent users of acupuncture are likely to suffer from diseases which might have also led to frequent intra-muscular injections or hospital admissions before universal availability of disposable syringes and needles.

In conclusion, although a fraction of HCV infections among people who underwent acupuncture may be due to other routes of parenteral transmission, we did find that a history of acupuncture was very frequent in South Korea and contributes to the high proportion of HCV seropositivity that we detected, especially among women. Safer acupuncture practice (i.e., use of disposable needles) represents, therefore, a high public health priority in South Korea and requires a close monitoring of acupuncturists nationwide.

\section{ACKNOWLEDGEMENTS}

The work reported in this paper was undertaken during the tenure of a Technical Transfer Award for HR Shin at the International Agency for Research on Cancer. 


\section{REFERENCES}

Ahn YO (1996) Strategy for vaccination against hepatitis B in areas with high endemicity: focus on Korea. Gut 38: S63-S66

Alter MJ (1999) Hepatitis C virus infection in the United States. J Hepatol 31: $88-91$

Alter MJ, Kruszon-Moran D, Nainan OV, McQuillan GM, Gao F, Moyer LA, Kaslow RA, Margolis HS (1999) The prevalence of hepatitis C virus infection in the United States, 1988 through 1994. N Engl J Med 341: 556-562

Dubois F, Desenclos J, Mariotte N, Goudeau A (1997) Hepatitis C in a French population-based survey, 1994: seroprevalence, frequency of viremia, genotype distribution, and risk factors. The Collaborative Study Group. Hepatology 25: 1490-1496

Fujiwara S, Kusumi S, Cologne J, Akahoshi M, Kodama K, Yoshizawa H (2000) Prevalence of anti-hepatitis C virus antibody and chronic liver disease among atomic bomb survivors. Radiat Res 154: $12-19$

Frank C, Mohamed MK, Strickland GT, Lavanchy D, Arthur RR, Magder LS, El Khoby T, Abdel-Wahab Y, Aly Ohn ES, Anwar W, Sallam I (2000) The role of parenteral antischistosomal therapy in the spread of hepatitis $\mathrm{C}$ virus in Egypt. Lancet 355: $887-891$

Goritsas C, Plerou I, Agaliotis S, Spinthaki R, Mimidis K, Velissaris D, Lazarou N, Labropoulou-Karatza C (2000) HCV infection in the general population of a Greek island: prevalence and risk factors. Hepatogastroenterology 47: $782-785$

Huh K, Choi SY, Whang YS, Lee DS (1998) Prevalence of viral hepatitis markers in Korean patients with hepatocellular carcinoma. J Korean Med Sci 13: $306-310$

IARC (1994) IARC monographs on the evaluation of carcinogenic risks to humans, Vol. 59, Hepatitis viruses. Lyon: International Agency for Research on Cancer

Kao JH, Chen DS (2000) Transmission of hepatitis C virus in Asia: past and present perspectives. J Gastroenterol Hepatol 15:(Suppl):): E91-E96

Kayaba K, Igarashi M, Okamoto H, Tsuda F (1998) Prevalence of anti-hepatitis $\mathrm{C}$ antibodies in a rural community without high mortality from liver disease in Niigata prefecture. J Epidemiol 8: 250-255

KIHSA (1999) Report of National Health and Nutrition Survey 1998. Seoul: Korea Institute for Health and Social Affairs

Kim MS, Seo KS, Kim NJ, Choi SK, Suh SP, Choi JS, Kim SJ (1997) A study on the positivities of anti-HCV by second-generation ELISA in rural area of Chonnam Province. Korean J Int Med 53: $741-746$

Kim YS, Pai CH, Chi HS, Kim DW, Min YI, Ahn YO (1992) Prevalence of hepatitis $\mathrm{C}$ virus antibody among Korean adults. J Korean Med Sci 7: $333-336$

Kiyosawa K, Tanaka E, Sodeyama T, Yoshizawa K, Yabu K, Furuta K, Imai H, Nakano Y, Usuda S, Uemura K, Furuta S, Watanabe Y, Watanabe J, Fukuda Y, Takayama Y (1994) Transmission of hepatitis C in an isolated area in Japan: community-acquired infection. The South Kiso Hepatitis Study Group. Gastroenterology 106: $1596-1602$

Lee DH, Kim JH, Han BH, Lee SO, Shin HR, Jung IC (2001) Geographical variation of liver cancer mortality in Korea (1992-1998). Cancer Res Treatment 33: $420-426$
Lee HS, Han CJ, Kim CY (1993) Predominant etiologic association of hepatitis $\mathrm{C}$ virus with hepatocellular carcinoma compared with hepatitis B virus in elderly patients in a hepatitis B-endemic area. Cancer 72: 2564-2567

Mezzetti M, Ferraroni M, Decarli A, La Vecchia C, Benichou J (1996) Software for attributable risk and confidence interval estimation in casecontrol studies. Comput Biomed Res 29: $63-75$

Michitaka K, Horiike N, Ohta Y (1991) An epidemiological study of hepatitis $\mathrm{C}$ virus infection in a local district in Japan. Rinsho Byori 39: $586-591$

Neal KR, Jones DA, Killey D, James V (1994) Risk factors for hepatitis C virus infection. A case-control study of blood donors in the Trent Regions (UK). Epidemiol Infect 112: 595-601

Okamoto H, Tokita H, Sakamoto M, Horikita M, Kojima M, lizuka H, Mishiro S (1993) Characterization of the genomic sequence of type V (or 3a) hepatitis c virus isolates and PCR primers for specific detection. J Gen Virol 74: 2385-2390

Raffaele A, Valenti M, Iovenitti M, Matani A, Bruno ML, Altobelli E, D’Alessandro A, Barnabei R, Leonardis B, Taglieri G (2001) High prevalence of $\mathrm{HCV}$ infection among the general population in a rural area of central Italy. Eur J Epidemiol 17: 41-46

SAS Institute Inc (1999) SAS/STAT User's Guide, Version 8. Vol. 2. Cary, North Carolina: SAS Institute Inc.

Seo TS, Lee SS (1998) A study on positive of HBsAg, HBsAB and anti-HCV in Korean adults. Korean J blood Transfu 9: 257-272

Shin HR, Kim JY, Ohno T, Cao K, Mizokami M, Risch H, Kim SR (2000) Prevalence and risk factors of hepatitis $\mathrm{C}$ virus infection among Koreans in a rural area of Korea. Hepatology Research 17: 185-196

Shin HR, Lee CU, Park HJ, Seol SY, Chung JM, Choi HC, Ahn YO, Shigemastu T (1996) Hepatitis B and C virus, Clonorchis sinensis for the risk of liver cancer: a case-control study in Pusan, Korea. Int J Epidemiol 25: 933 - 940

Sulaiman HA, Julitasari, Sie A, Rustam M, Melani W, Corwin A, Jennings GB (1995) Prevalence of hepatitis B and C viruses in healthy Indonesian blood donors. Trans R Soc Trop Med Hyg 89: 167-170

Sun C, Chen H, Lu C, You S, Mau Y, Ho M, Lin S, Chen C (1999) Transmission of hepatitis $\mathrm{C}$ virus in Taiwan: prevalence and risk factors based on a nationwide survey. J Med Virol 59: 290-296

WHO (1998) 1996 World Health Statistics. Geneva: World Health Organization

Yoo KY, Heon K, Lee MS, Park BJ, Ahn YO, Lee HS, Kim CY, Park TS (1991) A reconstructed cohort study on the hepatitis $\mathrm{B}$ virus infection as a risk factor of liver cancer in Korea. J Korean Med Sci 6: 319-324

Yoo KY, Shin HR, Chang SH, Lee KS, Park SK, Lee DH the KMCC Study Group (2002) Korean multi-center cancer cohort study: including a biological material bank (KMCC-1). Asian Pacific Journal of Cancer Prevention 3: $85-92$ 